\title{
On the Research of Flipped Teaching Mode for College English
}

\author{
Jinling Xia*
}

School of Foreign Language, Wuhan Technology and Business University, Wuhan 430065, China.

$$
\text { 517504104@qq.com }
$$

Abstract. As human society enters into the information age, education and teaching activities are more and more impacted by the information technology. With the emergence of new teaching concepts and teaching methods, the traditional teaching mode has been strongly challenged. This paper reflects on flipped teaching mode for college English, introducing the research background, theoretical basis of the flipped teaching mode as well as the content and significance of the research.

Keywords: Flipped teaching mode; College English.

\section{The Research Background}

\subsection{The Requirements of the Information Era}

At present, human society enters into the information age, education and teaching activities are more and more impacted by the information technology. Now new teaching concepts and teaching methods have been emerging continuously, and the traditional teaching model has been strongly challenged. Decade Development Plan of Education Information (2011-2020) puts forward clearly a new requirement that information technology and teaching be integrated. All of these have led to the renovation of teaching model. Under such a background, flipped classroom teaching mode have swept through the education field.

\subsection{Embarrassed Situation of Unproductive Teaching and Passive Learning}

The effect of English teaching has been unsatisfactory for a long time, but it is difficult to change the reality for there are too many problems to overcome. To a large class English teaching, it's extremely difficult for teachers to pay attentions to the students' individual differences, not to mention to teach in accordance with their aptitude. What's more, the activities of teacher input - student output is too dull and monotonous, making both teachers and students feel exhausted. In traditional English class, students tend to listen passively and lack awareness of active learning and inquiry, which makes English teaching dull and unproductive. If students are not highly motivated, teaching effect will not be achieved. So it is necessary to change the present teaching mode. The teachers should attempt to change the traditional education concept, know the requirements of the new curriculum reform, as well as master and adapt to the new teaching method. Thus the embarrassing situation of English teaching can be changed better step by step.

\subsection{Insufficient Utilization of Teaching Resources}

Since 2006, our college spent a lot of money on English autonomous learning center, including a major expenditure of network hardware and software environment as well as a large number of network learning resources, in order to satisfy the demands of teachers and students in the campus. However, English autonomous learning center has not been used efficiently all the time, and the learning effect produced by students is not satisfactory. In addition, another form of teaching resource has been neglected for a long time. That is, the network learning resources of New Horizon College English has been given no attention at all, so its online course does not promote diversified teaching mode, or it does not change the teachers' present teaching situation. Considering these problems, based on English autonomous learning center and New Horizon College online course as the platforms, this research aims to adopt flipped teaching mode to effectively change the teaching situation, in order to improve the present English teaching and learning. 


\section{The Research Status and Theoretical Basis of the Project}

\subsection{The Research Status}

The application of information technology to education has been overwhelming. As a new teaching mode, flipped teaching is born with the trend and conforms to the requirement of educational informationization in China. In recent years, flip teaching has become one of the hottest research topics. Initially flipped teaching is mainly discussed on the basic theory as well as its possible effect, such as its connotation, characteristics, development history and construction patterns, and effect of flipped teaching on education and how to play this role. (wang changjiang, 2013; Ding Jianying, 2014) As flip teaching draws more and more attention, its research becomes much further. Nowadays flipped teaching pattern design and evaluation of flipped teaching effect has gradually become the major trends for the research. (Zhang Jinlei, 2012; Liu Zhichao, 2016)On the whole, the problem of flipped teaching research remains that flipped teaching focus on "theoretical research, lack of empirical research, focus on the exploration of "pattern construction ", lack of "evaluation of its effectiveness ". (Duan chunyu, 2014)

In sum, this research aims to implement the flipped teaching, based on the double teaching platforms of English autonomous learning center and New Horizon College English online course. The research attempts to handle the problems of present English teaching. In the experiment of this research, flipped teaching and traditional face-to-face teaching will be compared to check out the effects and disadvantages of the two modes of teaching. On this basis, the two teaching modes are improved and integrated. In this way can a relatively ideal teaching mode be explored.

\subsection{Theoretical Foundation}

Qian Jiaxuan (2015) sums up the theoretical foundations of flipped teaching in seven types: constructivism learning theory, cognitive learning theory, cognitive assimilation learning theory, information-- processing learning theory, mastery learning theory, social learning theory, humanistic learning theory. This paper will focus on one of these theoretical foundations, that is mastery learning theory.

The author of mastery learning theory is Benjamin Bloom, a prominent American educationist and psychologist. He objects to the idea that "about a third of students will fully learn what they are taught", and he also did not agree with the conclusion that "learners' intelligence level tends to fellow a normal distribution". He believes that traditional teaching can not fully meet the need of each student's learning, resulting in great differences among students. He insists that teachers should create favorable conditions for students' learning and provide enough time for their study, "considering the individual differences and promoting each student's full development so as to reap a bumper harvest over large areas." (Zheng Jian, 1990)

In flipped teaching, with the help of information technology, students can learn flexibly and individualized learning is possible. According to their actual situation, students can study freely. If they feel difficult to accept the knowledge, they can watch the video or PPT again and again, even they can hold discussions between teachers and students before class or after class until they understand the difficult points. The flipped teaching ensures enough time for students to learn. What's more, flipped teaching is much more targeted based on the feedback of the students. The teacher can give individualized guidance according to the student's feedback. That's to say, as long as hardware and software support is available, students have good ability of independent learning, teachers have a good of design for classroom activity, mastery learning theory can get better implementation in teaching.

\section{The Research Content}

The mind map of the research content is as follows. 


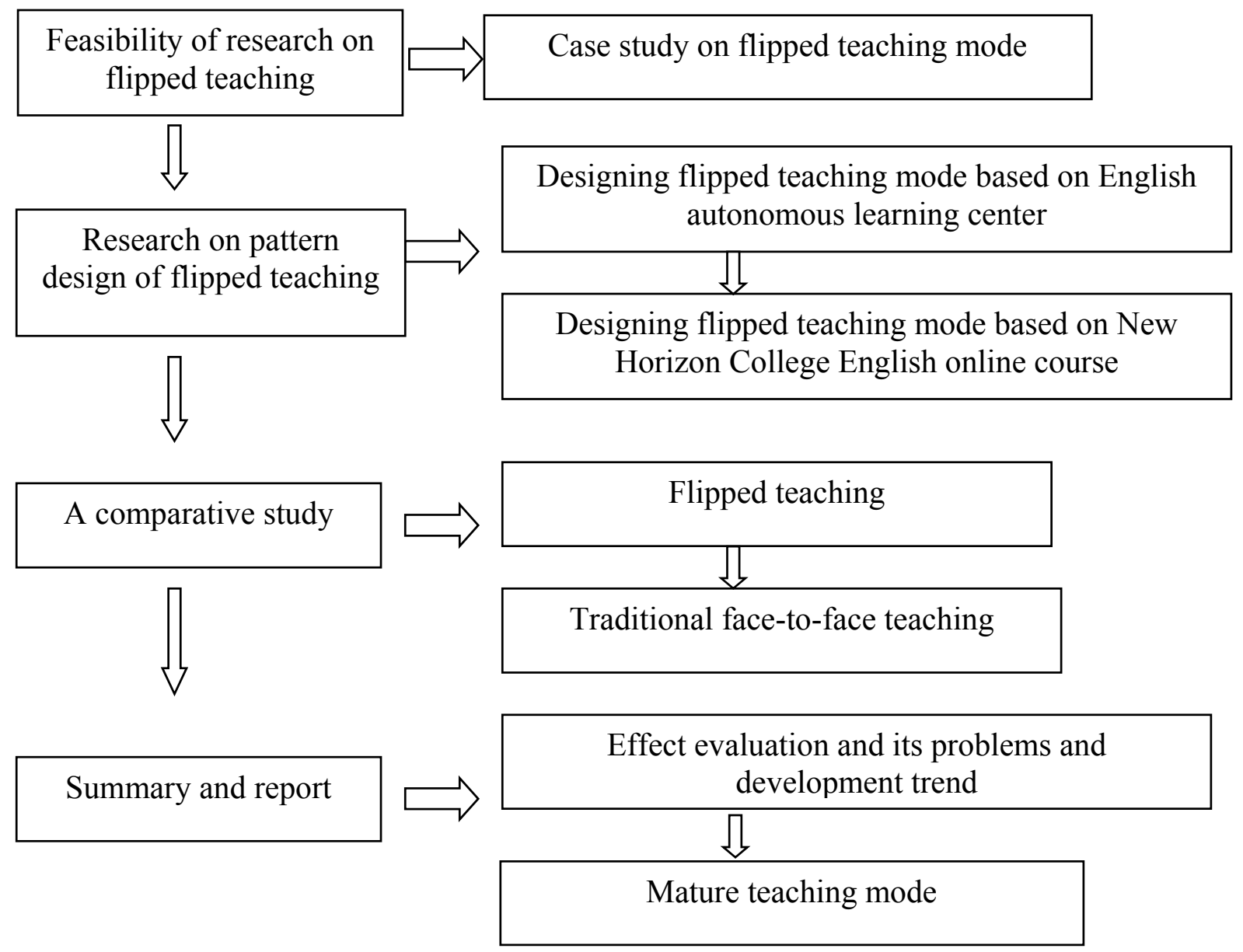

Figure 1. The mind map

\subsection{The Feasibility of Research}

In this step, the essence of flipped teaching must be deeply studied. Firstly, documents and materials on the application of flipped teaching mode in college teaching should be checked and read thoroughly. Then learn and command the experience of flipped teaching in theoretical research, learning environment construction and teaching design. Lastly check and confirm the feasibility of flipped teaching in the experiment of the campus.

\subsection{Research on Pattern Design}

Making full use of abundant learning resources available, such as English autonomous learning center as one platform, New Horizon College English online course as the other, students may choose flexibly the right platform for their own learning, according to their own situation. In order to make the most of both platforms, we will classify, compose, expand and supplement the existing learning resources on the two platforms, such as supplementing micro-video, audio, courseware, etc. On this basis, pre-class learning process, in-class knowledge internalization activity, after-class reflection and evaluation should be designed, thus the basic flipped teaching pattern in line with the characteristics of the college is formed. Then preliminary investigation and analysis of its feasibility and effectiveness should be done, after a rough estimate of the feasibility and effectiveness of the experiment, the next step will be carried out.

\subsection{A Comparative Study}

Choose two classes with no significant difference in academic performance and self-efficacy in a certain major, one as an experimental class and the other as a control class. Then in the teaching 
experiment, the experimental class is given flipped teaching, while the control class is given traditional face-to-face teaching. At the end of semester, learning test, questionnaire survey and interview are adopted to deeply understand the advantages and disadvantages of the two teaching modes and find out the problems that need to be improved. Thus modified teaching experiments will be done next term.

\subsection{Summary and Report}

After repeated teaching experiments, the results of study will finally be collected, sorted and analyzed so as to explore a mature teaching mode suited to the characteristics of the private colleges and universities students.

\section{Significance of the Research}

This research is conducive to improving the current situation of college English teaching in private colleges and universities. It not only makes full use of the existing teaching resources which have been undervalued before, but also conforms to the trend of education informatization. Besides, the research reports and results can provide reference for the English teaching reforms in other private colleges and universities, which helps to promote deep thinking and effective teaching reform of English teaching concepts, teaching methods and means as well as classroom activity design. This research is not only limited to promoting teachers' teaching, but also tries to reform students' learning. The purpose of the research is to complement the advantages of flipped teaching and traditional faceto-face teaching, which will be conducive to finding a more ideal teaching and learning mode. This teaching mode can effectively mediate the bad situation of students' lack of interest in English learning and can also greatly promote students' individualized learning and independent learning.

\section{Acknowledgements}

The author acknowledges the research grants from the program of Teaching Reform of Colleges and Universities in Hubei Province (2017482).

\section{References}

[1]. Qian Jajuan. Research of the Learning Theoretical Basis of Flipped Classroom [J].Science Guide, 2015, (10): 37-38.

[2]. Zheng Jian. On Bloom's Theory of Learning [J].Foreign Education Research, 1990, (1): 28-30.

[3]. Wang Changing. Flipped classroom: technology-driven teaching [J].Courses and Teaching, 2015, (8): 73-76.

[4]. Ding Jitneying. Research and Teaching Designing about Flipped Classroom [J].Curriculum Integration, 2013, (7): 88-91.

[5]. Zhao Jinee. Research on Flipped Classroom Teaching Model [J].Journal of Distance Education, 2014, (4):46-49.

[6]. Liu Zhuhai. Flipped Classroom Teaching Design Based on MOOC [J].Journal of South China University of Technology (Social Science Edition), 2016, (4):46-49.

[7]. Duane Chunky. Current Situation and Prospect of Domestic Flipped Classroom Study [J].Chongqing Higher Education Research, 2014, (7):106-112. 